\title{
Detection of inclined edge crack in prismatic beam using static deflection measurements
}

\author{
SUNIL R PANSARE ${ }^{1}$ and SACHIN S NAIK ${ }^{2, *}$ \\ ${ }^{1}$ Department of Mechanical Engineering, Dr. Babasaheb, Ambedkar Technological University, Lonere 402 103, \\ India \\ ${ }^{2}$ Department of Mechanical Engineering, Veermata Jijabai Technological Institute, Matunga, Mumbai 400019 , \\ India \\ e-mail: pansaresunil@gmail.com; ssnaik@me.vjti.ac.in
}

MS received 5 June 2017; revised 1 November 2017; accepted 6 September 2018; published online 1 February 2019

\begin{abstract}
The effectiveness of a static deflection method for detection of an inclined edge crack in a prismatic cantilever beam is presented in this paper. A rotational spring is used to represent the flexibility due to the inclined crack. Two values of static deflections are needed for detection of crack location and rotational spring stiffness. The spring is positioned at the crack tip. Twenty-one mild steel specimens with various crack inclinations, locations and depths are used for experimentation. The experimental results confirm that the static deflection measurements can be used to predict the crack location of an inclined edge crack with acceptable accuracy.
\end{abstract}

Keywords. Crack detection; inclined edge crack; static deflection measurements; open crack; rotational spring model.

\section{Introduction}

Mechanical components are expected to operate, in service, under different loading conditions. They are likely to develop cracks if loading conditions are severe. Cracks may also be present in the component due to manufacturing defects at surface and subsurface levels. It is essential that the damage is detected at an early stage to ensure safe and reliable operation. The presence of crack in a component results in change in its stiffness. This change in local stiffness has direct effect on static and dynamic behaviour of the component. Parameters like static deflection, natural frequencies, mode shapes, damping coefficient, etc., undergo changes. Such changes can be employed for developing non-destructive evaluation methods for monitoring the structural health and predicting crack location and severity of crack.

Vibration based techniques, which use changes in modal parameters for crack detection, are widely used. Most of these methods consider the crack as 'open', though few of them consider it as 'breathing' [1-4].

A crack on a loaded beam significantly increases the flexibility due to the strain energy concentration in the vicinity of the crack tip. A crack, therefore, can be macroscopically modelled as an elastic link connecting the two adjacent segments of a beam [5]. The elastic link can be a linear spring [6] or a rotational spring [7-9]. A

*For correspondence combination of linear and rotational springs has been used to represent the crack in a cracked Timoshenko beam [10].

Use of rotational spring to represent a crack is a very popular choice in modelling transverse or bending vibrations. Liang et al [8] studied transverse vibration problem of beams with various support conditions with edge normal crack. An 'open' crack is modelled by a rotational spring. Chaudhari and Maiti [11] used the rotational spring to represent a crack in segmented beams and Chinchalkar [12] used it in a beam with uniformly varying depth. Naniwadekar et al [13] used the rotational spring to model a transverse crack within a cross section in various angular orientations for slender pipes. Multiple crack detection methods using rotational spring approach and changes in natural frequencies are also presented [14, 15]. Lele and Maiti [16] used changes in natural frequencies to solve crack detection problem in Timoshenko beam. Lee and Chung [17] studied the influence of a crack on natural frequencies and mode shapes of a beam. Nguyen [18] investigated the influence of the coupling mechanism between horizontal bending and vertical bending vibrations due to the crack on the mode shapes. Lots of investigations on detection of single and multiple cracks are carried out using strain energy release rate (SERR) approach [19]. These methods use the knowledge of SIF for calculation of SERR to arrive at the flexibility matrix for the structures containing crack.

Crack detection methods based on static deflection measurements are also proposed by researchers. Data from 
previous works involving crack detection using changes in natural frequencies is compared by Jenkins et al [20]. The comparison of both theoretical and experimental frequency and deflection sensitivities are plotted for the transverse motion of a cantilever beam with crack modelled as a rotational spring. The authors remarked that though about $10 \%$ errors appeared in the results, they are due to numerical studies or laboratory experiments. The change in natural frequencies due to presence of crack is very small hence the sensitivity of such measurements for prediction of crack location or crack severity is limited. They further noticed that the static deflection measurements are often easier to make with higher levels of accuracy than dynamic measurements at least for simpler structural elements. It is observed that natural frequency is directly proportional to the square root of stiffness whereas static deflection is inversely proportional to stiffness [21]. Hence, a reduction of $1 \%$ in stiffness due to crack results in approximately $0.5 \%$ reduction in natural frequency but increase of almost $1 \%$ in static deflection. Thus better accuracy can be expected in crack detection process from measurements of static deflections than that of measurements of change in natural frequencies. A method using static deflection to identify single and multiple cracks in an elastic straight beam in bending for variety of boundary conditions is proposed by Caddemi and Morassi [22, 23]. The identification is based on an explicit expression of crackinduced variations in the deflection of beam with appropriate choice of pairs of static deflection measurements with respect to the crack position. In practice, since the measurement positions with respect to the crack are not known a priori, a grid of points along the beam axis to measure deflection was used and method was applied successively to detect the crack. A method for detection of a single edge normal crack in pipes using measurements of static deflections at two points on a slender beam in cantilever and simply supported configurations is presented by Naik [24].

Nandwana and Maiti [9] showed that an inclined edge crack can be detected using first three natural frequencies of the cracked beam. Natural frequencies of the beam were numerically obtained by the authors. They used rotational spring to model the crack.

In the present work, motivation is derived from the fact that the detection of inclined edge crack using static deflection measurements has not been reported in the literature. In this paper, rotational spring is used to represent the flexibility due to the presence of an inclined edge crack. Usefulness of static deflection measurements and rotational spring of model to represent an inclined edge crack is demonstrated to solve the crack detection problem.

\section{Theory}

In this paper, the method proposed by Naik [24] for detection of edge normal open crack in pipes is used to detect an inclined edge crack in prismatic cantilever beam. Figure 1

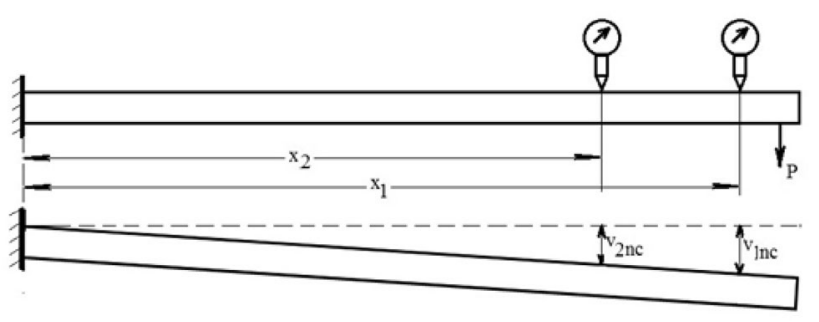

Figure 1. Schematic representation of two point static deflection measurement on crack-free beam [24].

shows a crack-free cantilever beam. Load is applied at the free end of the beam and corresponding static deflections are measured at two locations along the length of the beam.

For a crack-free cantilever beam of uniform cross section, the equation of deflection at any location $x$ from fixed support is given by

$$
v_{n c}=\frac{P x^{3}}{6 E I}-\frac{P L x^{2}}{2 E I}
$$

where $P$ is the load, $L$ is the length of the beam, $E$ is modulus of elasticity for the materials of the beam and $I$ is area moment of inertia of the beam cross-section.

At the two locations on a crack-free beam Eq. (1) will become,

$$
\begin{aligned}
& v_{n c}^{1}=\frac{P x_{1}^{3}}{6 E I}-\frac{P L x_{1}^{2}}{2 E I} \\
& v_{n c}^{2}=\frac{P x_{2}^{3}}{6 E I}-\frac{P L x_{2}^{2}}{2 E I}
\end{aligned}
$$

Superscripts 1 and 2 of $v_{n c}$ refer to the two locations $x_{1}$ and $x_{2}$ where static deflection measurements are taken. The deflections given by Eqs. (2) and (3) form the basis for measurements made on beam with a crack.

Figure 2 shows the cantilever beam with an inclined crack. The crack is represented by a rotational spring of stiffness $K$ at the tip of the crack. The crack tip is located at

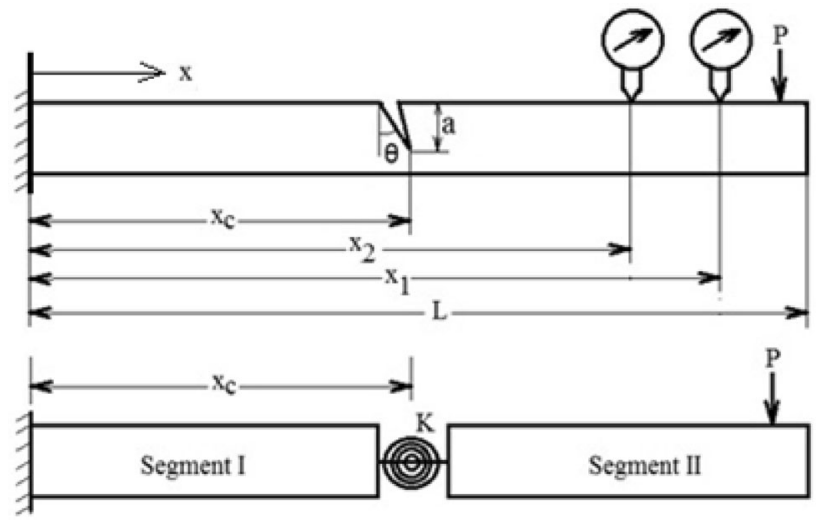

Figure 2. Representation of inclined edge crack by rotational spring. 


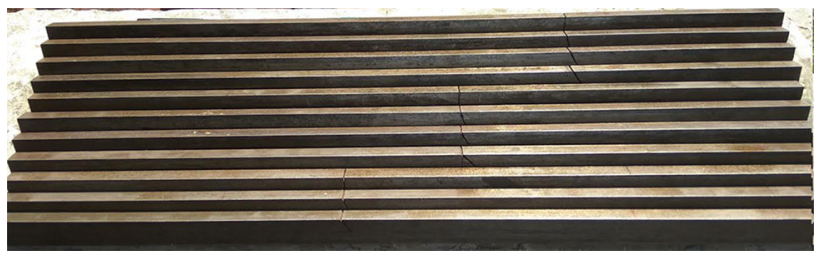

Figure 3. The cracked specimens with inclined crack.

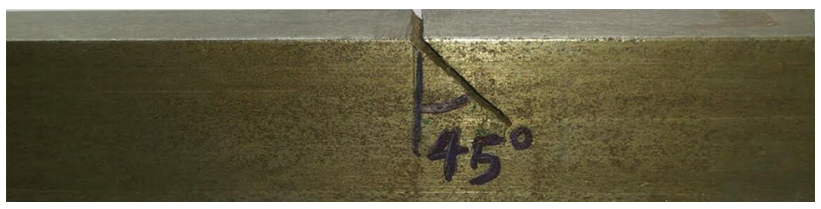

Figure 4. Specimen with crack inclined at $+45^{\circ}$.

distance $x_{c}$ from the fixed end and the crack makes an angle $\theta$ with vertical. The crack depth $a$ is measured normal to the edge of the beam. The rotational spring connects segments I and II. The deflection of the beam in segment I using Eq. (1) will become

$$
v_{I c}=-\frac{P x_{c}^{2}}{6 E I}\left(3 L-x_{c}\right)
$$

The deflection of the segment II includes slope of segment I and jump in the slope at crack location due to the presence of crack. Thus slope of section II is given by

$$
\frac{d v_{I I c}}{d x}=\frac{d v_{I c}}{d x}+\frac{M}{K}
$$

where $M$ is moment due to applied load produced at the crack tip. Subscripts I and II refer to segments I and II, respectively. Further, using compatibility of displacements, the deflection in segment II will be

$$
v_{I I c}=-\frac{P L x^{2}}{2 E I}+\frac{P x^{3}}{6 E I}-\frac{M}{K}\left(x-x_{c}\right) \text { for } x_{c} \leq x \leq L
$$

The additional deflection due to the presence of a crack in segment II at location $i$ can be written as

$$
\delta v_{i}=\left(v_{I I c}\right)_{i}-v_{n c}^{i} \text { for } x_{c} \leq x \leq L
$$

where index $i=1$ to 2 for the two locations of deflection measurement.Using Eqs. (2), (3), (6) and (7), the ratio of change in deflection at locations 1 and 2 can be written as

$$
\frac{\delta v_{1}}{\delta v_{2}}=\frac{\left(x_{1}-x_{c}\right)}{\left(x_{2}-x_{c}\right)}=r(\text { say })
$$

Thus, expression for crack location can be written as,

\begin{tabular}{|c|c|c|c|c|c|}
\hline \multirow{2}{*}{$\begin{array}{l}\text { Specimen } \\
\text { number }\end{array}$} & \multirow{2}{*}{$\begin{array}{c}\text { Crack } \\
\text { inclination, } \\
\theta\end{array}$} & \multicolumn{4}{|c|}{ Normalised crack location, $\beta$} \\
\hline & & $\mathrm{a} / \mathrm{h}=0.15$ & $\mathrm{a} / \mathrm{h}=0.3$ & $\mathrm{a} / \mathrm{h}=0.4$ & $\mathrm{a} / \mathrm{h}=0.5$ \\
\hline 1 & $0^{\circ}$ & 0.2 & 0.2 & 0.2 & 0.2 \\
\hline 2 & $0^{\circ}$ & 0.4 & 0.4 & 0.4 & 0.4 \\
\hline 3 & $0^{\circ}$ & 0.6 & 0.6 & 0.6 & 0.6 \\
\hline 4 & $+15^{\circ}$ & 0.202 & 0.204 & 0.2054 & 0.2067 \\
\hline 5 & $+15^{\circ}$ & 0.402 & 0.404 & 0.4054 & 0.4067 \\
\hline 6 & $+15^{\circ}$ & 0.602 & 0.604 & 0.6054 & 0.6067 \\
\hline 7 & $+30^{\circ}$ & 0.2043 & 0.2087 & 0.2115 & 0.2144 \\
\hline 8 & $+30^{\circ}$ & 0.4043 & 0.4087 & 0.4115 & 0.4144 \\
\hline 9 & $+30^{\circ}$ & 0.6043 & 0.6087 & 0.6115 & 0.6144 \\
\hline 10 & $+45^{\circ}$ & 0.2075 & 0.215 & 0.22 & 0.225 \\
\hline 11 & $+45^{\circ}$ & 0.4075 & 0.415 & 0.42 & 0.425 \\
\hline 12 & $+45^{\circ}$ & 0.6075 & 0.615 & 0.62 & 0.625 \\
\hline 13 & $-15^{\circ}$ & 0.198 & 0.196 & 0.1946 & 0.1933 \\
\hline 14 & $-15^{\circ}$ & 0.398 & 0.396 & 0.3946 & 0.3933 \\
\hline 15 & $-15^{\circ}$ & 0.598 & 0.596 & 0.5946 & 0.5933 \\
\hline 16 & $-30^{\circ}$ & 0.1957 & 0.1913 & 0.1885 & 0.1856 \\
\hline 17 & $-30^{\circ}$ & 0.3957 & 0.3913 & 0.3885 & 0.3856 \\
\hline 18 & $-30^{\circ}$ & 0.5957 & 0.5913 & 0.5885 & 0.5856 \\
\hline 19 & $-45^{\circ}$ & 0.1925 & 0.185 & 0.18 & 0.175 \\
\hline 20 & $-45^{\circ}$ & 0.3925 & 0.385 & 0.38 & 0.375 \\
\hline 21 & $-45^{\circ}$ & 0.5925 & 0.585 & 0.58 & 0.575 \\
\hline
\end{tabular}

$$
x_{c}=\frac{\left(x_{1}-r x_{2}\right)}{(1-r)}
$$

and, for rotational spring stiffness as,

Table 1. Details of specimens used. 


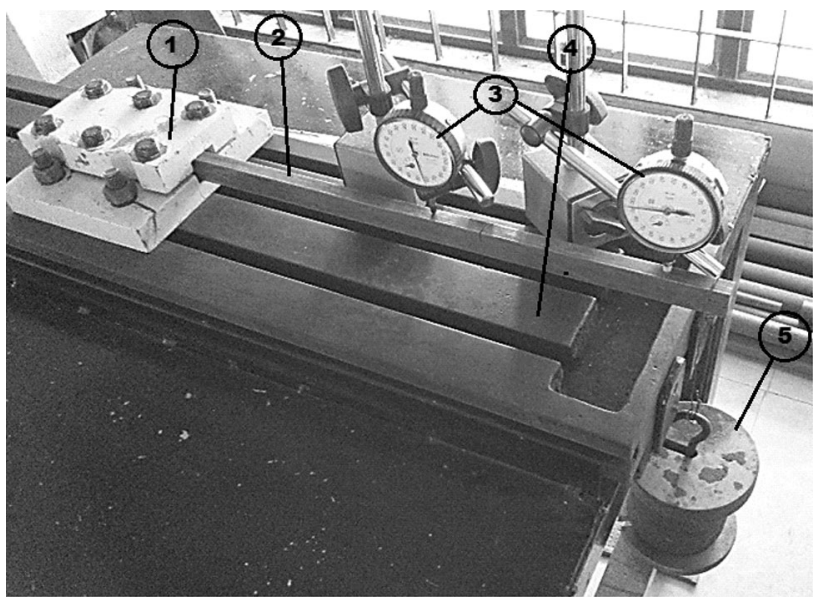

Figure 5. Photograph of experimental set-up.

$$
K=\frac{-P\left(L-x_{c}\right)\left(x_{1}-x_{c}\right)}{\delta v_{1}} \text { or } K=\frac{-P\left(L-x_{c}\right)\left(x_{2}-x_{c}\right)}{\delta v_{2}}
$$

Eqs. (9) and (10) can be employed for detection of an inclined crack and the rotational spring stiffness.

\section{Experimental work}

Detection of crack is based on comparison of static deflection measurements of crack-free and cracked specimens. Accordingly, during the experimentation, measurements are taken on specimen with and without crack. One crack-free and twenty-one specimens with crack are used. The specimens have rectangular cross section and are in cantilever configuration. The crack in the specimens is made using jeweller's saw. Figure 3 shows a few cracked specimens. Cracks are made in different orientations; the crack inclination is taken positive when it is in the counterclockwise direction from the vertical and negative when it is in the clockwise direction (figure 2 shows a crack in positive inclination). Figure 4 shows close-up of a crack in a beam oriented in $+45^{\circ}$ orientation. Cracks are made with different depths and locations in the specimens. The geometric details of the specimens with crack are given in table 1.

All the specimens are $400 \mathrm{~mm}$ long and their crosssection is $12 \mathrm{~mm} \times 20 \mathrm{~mm}(w \times h)$. They are made of mild steel-the modulus of elasticity is taken as $210 \mathrm{GPa}$ and density as $7860 \mathrm{~kg} / \mathrm{m}^{3}$. Figure 5 shows photograph of the actual experimental setup. The setup consists of a fixture (1), specimen (2), Mitutoyo make two dial indicators (least count of 1 micron) with magnetic stand (3), rigid table (4) and weight pan (5).

During experimentation, readings from the two dial indicators are recorded for the applied load. First dial indicator measures deflection of a point at location $270 \mathrm{~mm}$ and the second of a point at $360 \mathrm{~mm}$ from the fixed end. Note that both locations lie within segment II. Load pan is attached at a distance of $10 \mathrm{~mm}$ from the free end. For both crack-free and cracked beams, the load is applied in the steps of $1 \mathrm{~kg}$ up to maximum of $4 \mathrm{~kg}$. For each specimen about 20 readings are taken and the average of these values is used for predictions.

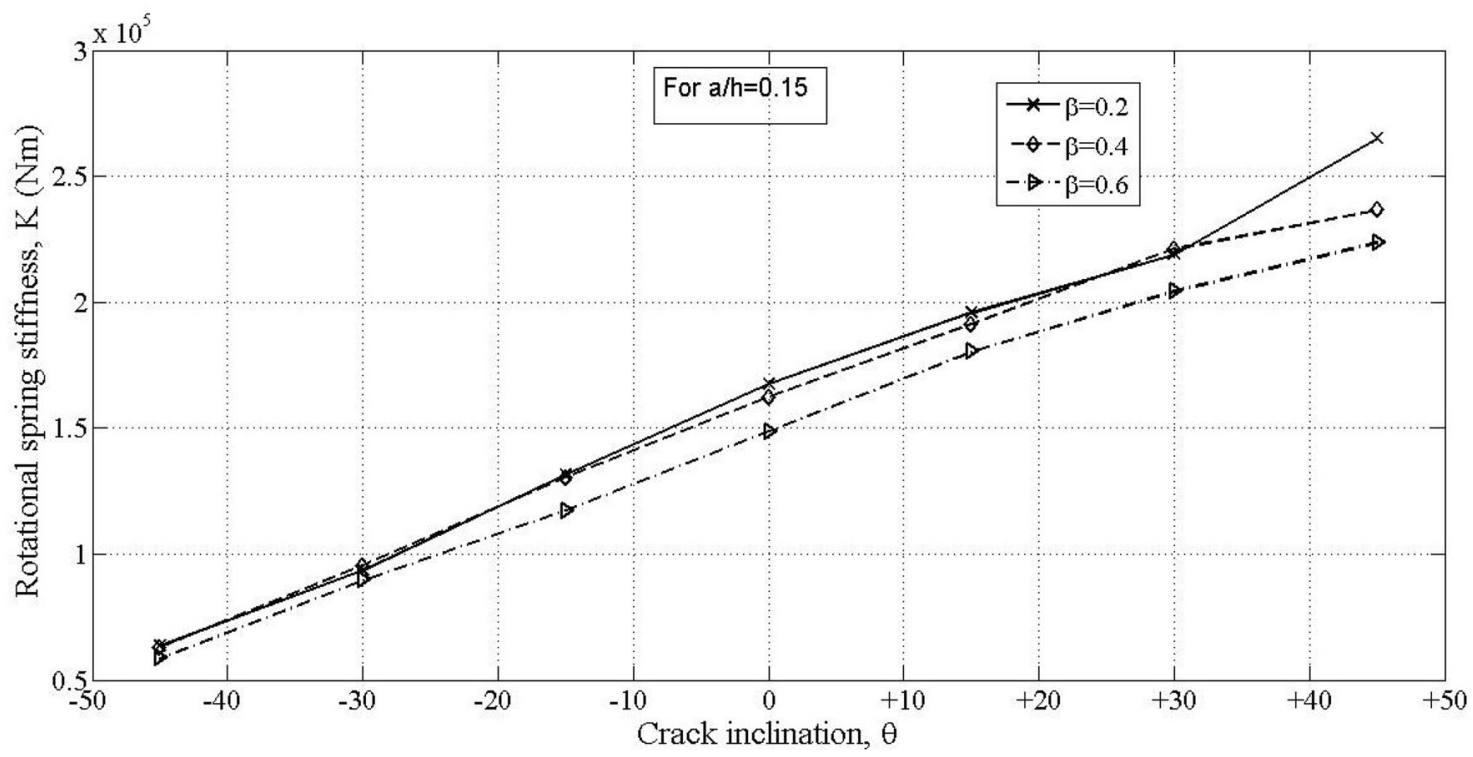

Figure 6. Variation of rotational spring stiffness with crack angle. 


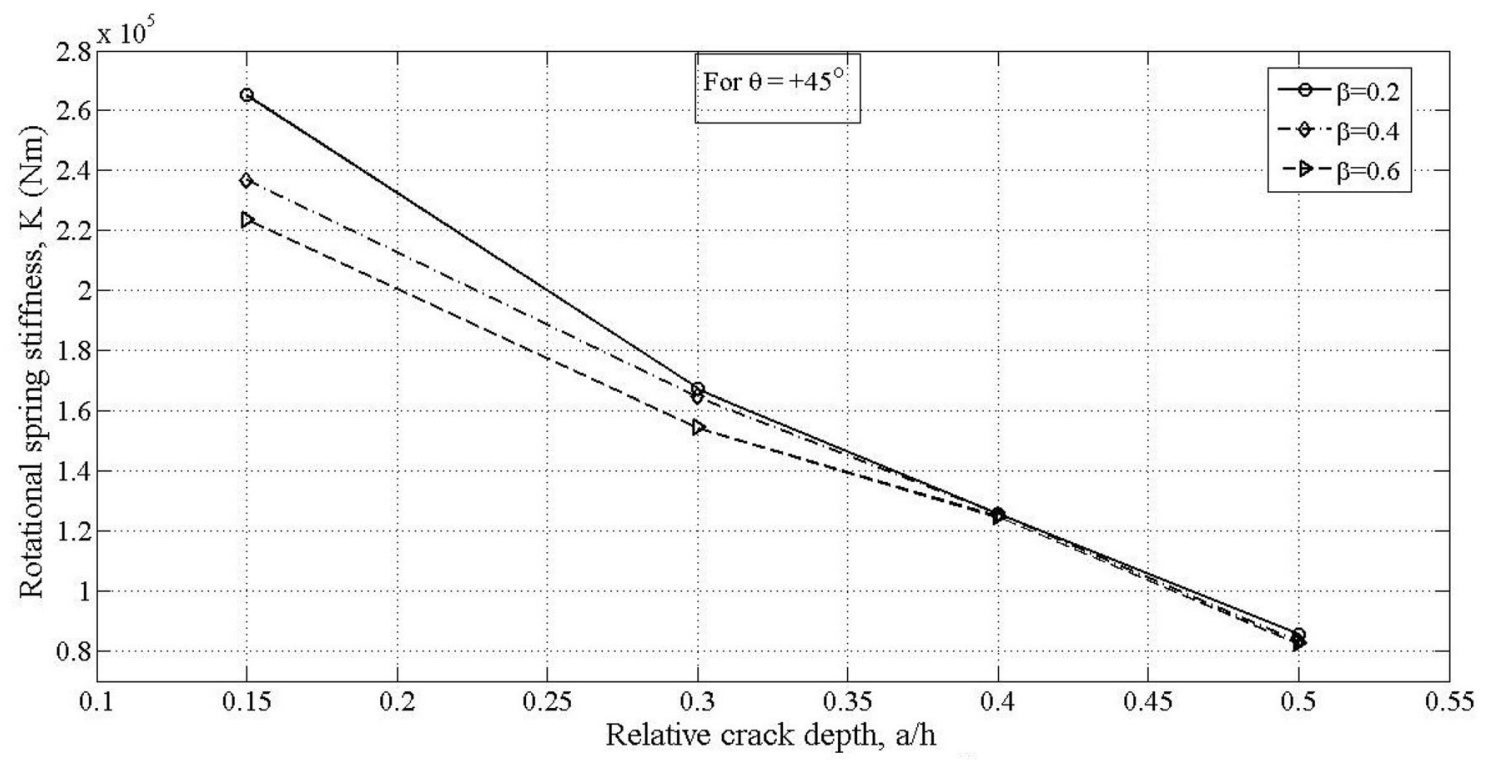

Figure 7. Variation of rotational spring stiffness with relative crack depth.

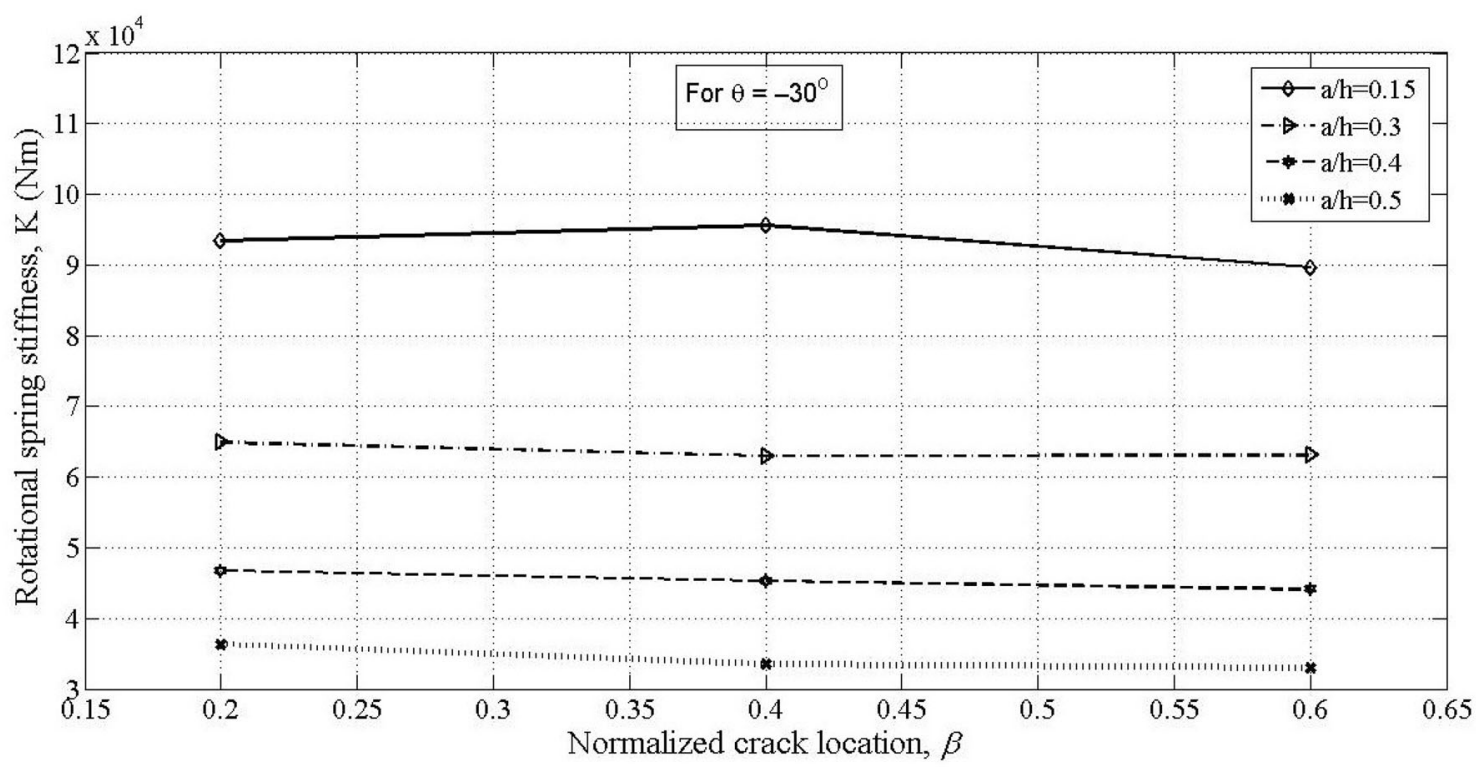

Figure 8. Variation of rotational spring stiffness with relative crack location.

\section{Results and discussion}

The measured static deflection values are used to predict the crack location and rotational spring stiffness using Eqs. (9) and (10). Figure 6 shows variation of rotational spring stiffness with the inclination of the crack. It clearly shows that as the angle of the crack increases in positive direction, the stiffness of the cracked beam increases in comparison with the crack in $0^{\circ}$ inclination. Also, as the angle of the crack increases in the negative direction from $0^{\circ}$, the rotational spring stiffness decreases. The change in stiffness with respect to crack angle from $-45^{\circ}$ to $+45^{\circ}$ is increasing. This is because the distance between the dial gauges (which are at the fixed locations) and the crack tip changes with crack angle. The crack tip shifts closer to these dial gauge locations as the crack angles changes from $-45^{\circ}$ to $+45^{\circ}$. For this reason, the static deflections decrease as the crack moves in this manner. This causes the stiffness to rise as the crack angle changes from $-45^{\circ}$ to $+45^{\circ}$. 


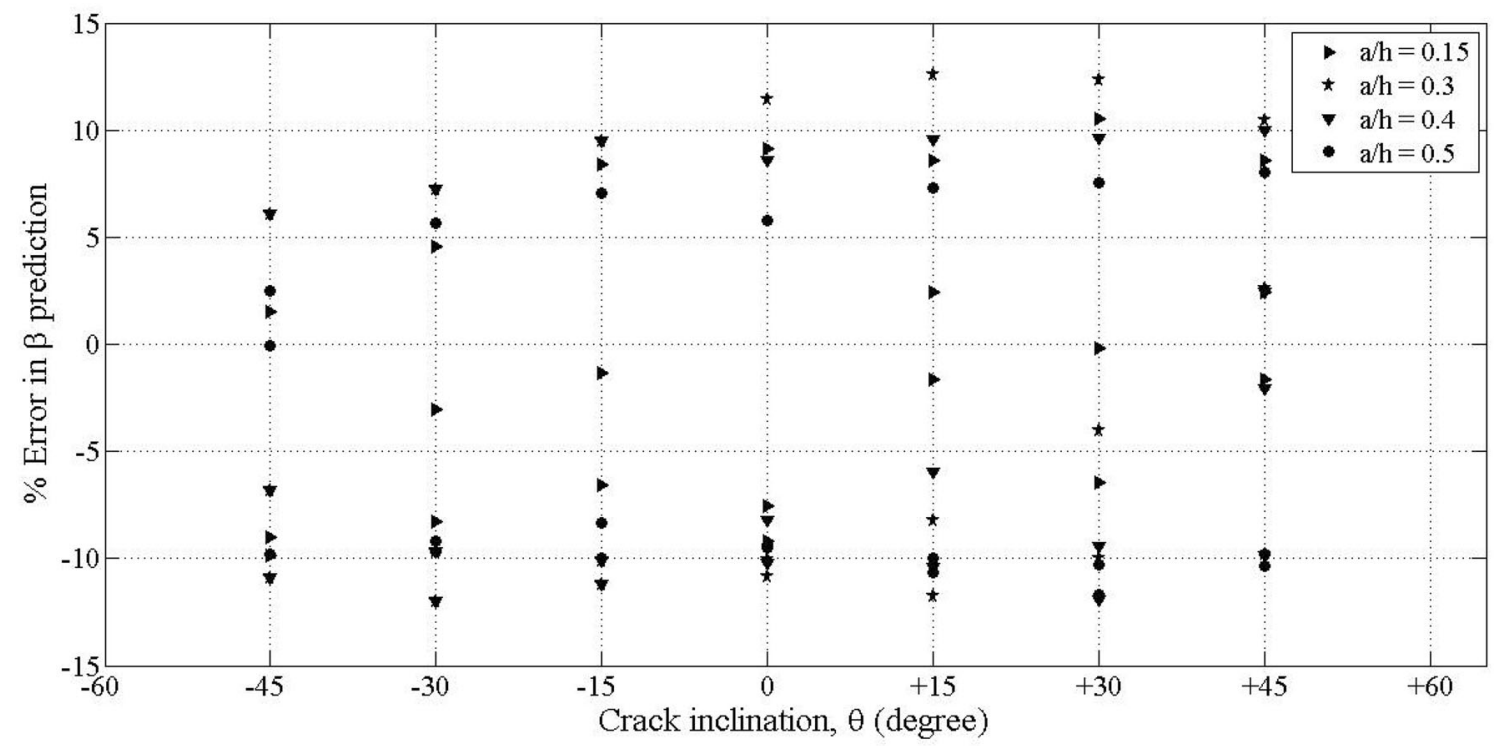

Figure 9. Scatter of relative error for all predicted crack locations and all $\beta$.

It is obvious that as crack depth increases, the structure becomes more flexible. It can be observed from figure 7 that for all values of the crack inclinations and relative crack locations, the values of rotational spring stiffness decrease as crack depth increases.

Figure 8 shows that the crack location has marginal effect on the rotational spring stiffness. The same trend is observed for all other values of crack angle. This is in agreement with the fact that rotational spring stiffness of a crack depends on crack depth and inclination and is independent of crack location. Thus the observed marginal variation in the rotational spring stiffness can be attributed to the errors involved in experimentation.

All obtained experimental values of rotational spring stiffness are used for developing its correlation with relative crack depth and crack angle as follows:

$$
\begin{aligned}
K= & {\left[2.142-4.076\left(\frac{a}{h}\right)+0.02553 \theta+1.878\left(\frac{a}{h}\right)^{2}\right.} \\
& \left.-0.0382\left(\frac{a}{h}\right) \theta-\left(2.33 \times 10^{-5}\right) \theta^{2}\right] \times 10^{5}
\end{aligned}
$$

$K$ is in N-m and $\theta$ is in degree with \pm sign as applicable. $M A T L A B R 2015 a$ is used to obtain the correlation with correlation coefficient as 0.9912 .

Figure 9 shows relative error in all predicted values of $\beta$ for all the inclinations of the crack. The experimental results with all specimens predict relative crack location with about $\pm 10 \%$ relative error.

\section{Conclusions}

Static deflection measurements of a cantilever beam can be used for predicting location of an inclined edge crack in conjunction with a rotational spring model to represent the inclined crack. Relative error in predicting the crack location is mostly about $\pm 10 \%$ - the maximum value is found to be $+12.61 \%$. It is found that the rotational spring stiffness increases as crack inclination angle varies from $-45^{\circ}$ to $+45^{\circ}$. Further, rotational spring stiffness decreases, as expected, as crack depth increases for all values of the crack inclination angle and relative crack locations. The rotational spring stiffness is found to be independent of the crack location.

\section{References}

[1] Doebling S W, Farrar C R, Prime M B and Shevitz D W 1996 Damage identification and health monitoring of structural and mechanical systems from changes in their vibration characteristics: A literature review. Los Alamos National Laboratory report, LA-13070-MS

[2] Yan Y J, Chengb L, Wua Z Y and Yamb L H 2007 Development in vibration-based structural damage detection technique. Mech. Syst. Signal Process. 21: 2198-2211

[3] Georgantzinos S K and Anifantis N K 2008 An insight into the breathing mechanism of a crack in a rotating shaft. $J$. Sound Vib. 318: 279-595

[4] Giannopoulos G I, Georgantzinos S K and Anifantis N K 2015 Coupled vibration response of a shaft with a breathing crack. J. Sound Vib. 336: 191-206

[5] Gounaris G and Dimarogonas A 1988 A fintite element of a cracked prismatic beam for structural analysis. Comput. Struct. 28(3): 309-313

[6] Adams R D, Cawley P, Pye C J and Stone B J 1978 A vibration technique for non-destructively assessing the integrity of structures. J. Mech. Eng. Sci. 20: 93-100

[7] Chondras T G and Dimarogonas A D 1980 Identification of cracks in welded joints of complex structures. J. Sound Vib. 69: $531-538$ 
[8] Liang R Y, Choy F K and Hu J 1991 Detection of cracks in beam structures using measurements of natural frequencies. J. Frankl. Inst. 328: 505-518

[9] Nandwana B P and Maiti S K 1997 Detection of the location and size of a crack in stepped cantilever beams based on measurements of natural frequencies. J. Sound Vib. 203: 435-446

[10] Loya J A, Rubio L and Fernandez-Saez J 2006 Natural frequencies for bending vibrations of Timoshenko cracked beams. J. Sound Vib. 290: 640-653

[11] Chaudhari T D and Maiti S K 2000 A study of vibration of geometrically segmented beams with and without crack. Int. J. Solids Struct. 37: 761-779

[12] Chinchalkar S 2001 Determination of crack location in beams using natural frequencies. J. Sound Vib. 247: 417429

[13] Naniwadekar M R, Naik S S and Maiti S K 2008 On prediction of crack in different orientations in pipe using frequency based approach. Mech. Syst. Signal Process. 22: 693-708

[14] Morassi A and Rollo M 2001 Identification of two cracks in a simply supported beam from minimal frequency measurements. J. Vib. Control 7: 729-739

[15] Khiem N T and Lien T V 2001 A simplified method for natural frequency analysis of a multiple cracked beam. $J$. Sound Vib. 245: 737-751
[16] Lele S P and Maiti S K 2002 Modeling of transverse vibration of short beams for crack detection and measurement of crack extension. J. Sound Vib. 257: 559-583

[17] Lee Y S and Chung M J 2000 A study on crack detection using eigen frequency test data. Comput. Struct. 77: 327-342

[18] Nguyen K V 2014 Mode shapes analysis of a cracked beam and its application for crack detection. J. Sound Vib. 333: 848-872

[19] Papadopoulos C A 2008 The strain energy release approach for modeling cracks in rotors: A state of the art review. Mech. Syst. Signal Process. 22: 763-789

[20] Jenkins C H, Kjerengtroen L and Oestensen H 1997 Sensitivity of parameter changes in structural damage detection. Shock Vib. 4: 27-37

[21] Bachschmid N, Pennacchi P and Tanzi E 2010 Cracked rotors: A survey on static and dynamic behaviour including modelling and diagnosis. Berlin, Heidelberg: Springer-Verlag Rotor testing for crack detection, page 41

[22] Caddemi S and Morassi A 2007 Crack detection in elastic beams by static measurements. Int. J. Solids Struct. 44: 5301-5315

[23] Caddemi S and Morassi A 2011 Detecting multiple open cracks in elastic beams by static tests. J. Eng. Mech. 137: 113-124

[24] Naik S S 2012 Crack detection in pipes using static deflection measurements. J. Inst. Eng. India Ser. C 93: 209-215 